\title{
Transposition and Toric Transposition
}

\section{Partha Haradhan Chowdhury ${ }^{1 *}$, Brinda Haren Shah ${ }^{2}$ and Nripesh}

\section{Tiwari ${ }^{3}$}

1M.Optom, Associate Professor, Principal, Department of Optometry, Shree Satchandi

\section{Short Communication}

Volume 3 Special Issue 1

Received Date: September 11, 2018

Published Date: October 03, 2018

Jankalyan Samiti Netra Prasikshan Sansthan, Pauri, Affiliated to Uttarakhand State Medical Faculty, Dehradun, India

${ }^{2}$ M.Optom, Guest Lecturer, Department of Optometry, Shree Satchandi Jankalyan Samiti Netra Prasikshan Sansthan, Pauri, Affiliated to Uttarakhand State Medical Faculty, Dehradun, India

${ }^{3}$ D.Optom, General Secretary and Chief Optometrist, Department of Optometry, Shree Satchandi Jankalyan Samiti Netra Prasikshan Sansthan, Pauri, Affiliated to Uttarakhand State Medical Faculty, Dehradun, India

*Corresponding author: Partha Haradhan Chowdhury, M. Optom, Department of Optometry, Shree Satchandi Jankalyan Samiti Netra Prasikshan Sansthan, Pauri, Affiliated to Uttarakhand State Medical Faculty, Dehradun, India, Email: optometrypublish@gmail.com

\section{Introduction}

\section{Rules for Transposition}

Axis will be changed from the 90 degree apart

$>$ Cylinder sign will be changed

$>$ Cylinder value will remain same

$>$ Spherical power will be adjusted to cylinder value

\section{Examples}

A. +4.00 Ds / +4.00 Dcyl*90

$>$ Rule about Axis - Here, axis will be 180

$>$ Cylinder sign - Here, cylinder value will be in minus form

$>$ Cylinder value will be same

$>$ Spherical power will be adjusted to spherical value

Here, $[+4.00+(+4.00)]=[+8.00]$

$>$ So, final answer will be

+8.00 Dsph / -4.00 Dcyl*180

B. $\quad+8.00$ Dsh/-4.00 Dcyl*90

$>+8.00+(-4.00) /+4.00 * 180$

$+(8.00)-(4.00) /+4.00 * 180$

$+4.00 /+4.00 * 180$

\section{Toric Transposition}

\section{Example 1}

First Step

Prescription cylinder sign will be matched with the base curve sign.

Eg:

Suppose: [Base curve $=-6.00]$

Prescription: $-2.00 /+5.00 * 180$

Here, Base curve is in minus form and prescription cylinder is in plus form, so transposition is needed [1].

$-2.00+(+5.00) /-5.00 * 90$

$>+3.00 /-5.00 * 90$

\section{Second Step}

Always minus will be done between Base curve and spherical power.

Here, spherical power is $+3.00 \mathrm{D}$ and Base curve is $-6.00 \mathrm{D}$

So, $+3.00-(-6.00)$

$>+3.00+6.00$

$>+9.00$

It will be used on the tool.

\section{Third Step}

Base curve axis will be completely perpendicular to the final prescription axis (after transposed) [2]. 


\section{Open Access Journal of Ophthalmology}

So, $-6.00 * 180$

Fourth Step

Always addition will be done between Base Curve and cylinder [3].

So,

$>\mathrm{BC}=-6.00$

$>$ Cylinder $=-5.00$

$>-6.00+(-5.00) * 90$

$>-6.00-5.00 * 90$

$>-11.00 * 90$

Final,

$+9.00$

$-6.00 * 180 /-11.00 * 90$

Example 2

Prescription $-3.00 /+5.00 * 90$

Base curve -6.00

\section{First Step}

Transpose the prescription so that base curve sign will be similar to the base curve sign

$>+2.00 /-5.00 * 180$

\section{Second Step}

Minus should be done between spherical and base curve power.

$>-6.00-(+2.00)$

$-6.00-2.00$
$-8.00$

It will be used in a tool

Third Step

Base curve axis will be completely perpendicular with the prescription (which is transposed)

So, axis will be

$>-6.00 * 90$

Fourth Step

Add Base curve and cylinder power

$>-6.00+(-5.00) * 180$

$>-11.00 * 180$

So, final

$-8.00$

$-6.00 * 90 /-11.00 * 180$

\section{References}

1 William J Benjamin (2006) Borish's Clinical Refraction 2nd (Edn.).

2 Theodore Grosvenor, Theodore P Grosvenor (2007) Primary Care Optometry. $5^{\text {th }}$ (Edn.).

3 Sir Stewart Duke-Elder, David Abrams (1978) DukeElder's Practice of refraction. 